\title{
Biowaste-derived substances as a tool for obtaining magnet-sensitive materials for environmental applications in wastewater treatments
}

\author{
Flavia Franzoso ${ }^{a}$, Roberto Nisticò ${ }^{\mathrm{a}, *}$, Federico Cesano $^{\mathrm{a}, \mathrm{b}}$, Ingrid Corazzari ${ }^{\mathrm{a}, \mathrm{b}, \mathrm{c}}$, Francesco Turci ${ }^{\mathrm{a}, \mathrm{b}, \mathrm{c}}$, \\ Domenica Scarano ${ }^{\mathrm{a}, \mathrm{b}}$, Alessandra Bianco Prevot ${ }^{\mathrm{a}}$, Giuliana Magnacca ${ }^{\mathrm{a}, \mathrm{b}}$, Luciano Carlos ${ }^{\mathrm{d}}$, Daniel O. Mártire ${ }^{\mathrm{e}}$ \\ ${ }^{a}$ University of Torino, Department of Chemistry, Via P. Giuria 7, 10125 Torino, Italy \\ ${ }^{\mathrm{b}}$ NIS Interdepartmental Centre, Via P. Giuria 7, 10125 Torino, Italy \\ c “G. Scansetti” Interdepartmental Centre for Studies on Asbestos and other Toxic Particulates, Via P. Giuria 7, 10125 Torino, Italy \\ d Instituto de Investigación y Desarrollo en Ingeniería de Procesos, Biotecnología y Energías Alternativas, PROBIEN (CONICET-UNCo), Buenos Aires 1400, Neuquén, Argentina \\ e Instituto de Investigaciones Fisicoquímicas Teóricas y Aplicadas (INIFTA), Universidad Nacional de La Plata, Casilla de Correo 16, Sucursal 4, 1900 La Plata, Argentina
}

\section{H I G H L I G H T S}

- Biowaste substances (BBS) were used as stabilizers for the production of magnetic NPs.

- TGA-FTIR analysis of evolved gas was performed to evaluate materials composition.

- Photo-activity of BBS-stabilized NPs was tested under (photo-)Fenton conditions.

- Good performances in caffeine abatement were obtained at circumneutral $\mathrm{pH}$.

- Results clearly highlight the BBS capacity as enhancing agent in AOP treatments.

\section{A R T I C L E I N F O}

Article history:

Received 15 July 2016

Received in revised form 25 October 2016 Accepted 27 October 2016

Available online $\mathrm{xxxx}$

\section{Keywords:}

Biomasses valorization

Emerging pollutants

Iron oxides

Magnetic materials

Fenton and Photo-Fenton reactions
G R A P H I C A L A B S T R A C T

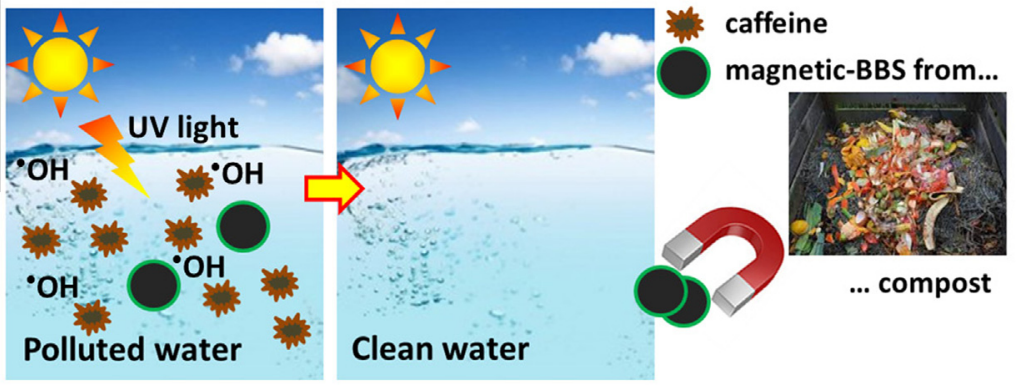

\begin{abstract}
A B S T R A C T
In this study, bio-based substances (BBS) obtained from composted urban biowaste are used as stabilizers for the synthesis of magnet-sensitive nanoparticles (NPs). The BBS-stabilized NPs are characterized by means of different techniques (FTIR, XRD, SEM, BET analysis, magnetization curves). Additionally, TGA coupled on-line with FTIR and GC/MS analysis of the exhausted gas are performed in order to simultaneously identify all the degradation products and evaluate the exact composition of such BBS-stabilized materials. Moreover, Fenton-like or photo-Fenton-like experiments carried out at circumneutral pH are performed in order to evaluate the BBS-functionalized NPs photo-activity towards the degradation of caffeine (taken as model emerging pollutant). The obtained promising results encourage the use of BBS as a green alternative tool for the preparation of smart materials with enhanced magnet-sensitive properties, also suitable for applications in wastewater purification treatments.
\end{abstract}

(c) 2016 Elsevier B.V. All rights reserved.

\footnotetext{
* Corresponding author.

E-mail address: roberto.nistico@unito.it (R. Nisticò).
}

\section{Introduction}

Together with the human technological expansion, there is a significant increasing of the anthropogenic impact on water sources, thus creating a dramatic reduction of the available resources [1]. In fact, even though the primary renewable source 
of fresh water is the continental rainfall, which generates a global supply of $40,000-45,000 \mathrm{~km}^{3}$ per year, this is not enough to fulfill the increasing demand caused by human population growing [2]. Besides this, one of the major problems related to fresh water quality is represented by pollutants contamination, difficult to remove by the traditional treatments $[3,4]$. Among the more classic pollutants, a wide group of anthropic chemical substances named emerging pollutants (EPs), whose dangerousness is only recently recognized but not yet regulated by environmental laws, is receiving great attention from the scientific community (i.e. human pharmaceuticals and veterinary medicines, nanomaterials, personal-care products, paints and coatings) [5-7].

In order to solve this issue, many studies focused on innovative wastewater treatments are being carried out currently, for instance the exploitation of no-cost bio-based sources (i.e. microalgae, biomasses and humic/fulvic acids, chitosan and its derivatives, etc.) as novel adsorbents/active species for the removal of EPs which is very promising allowing both economic and environmental benefits [8-12].

At the same time, advanced oxidation processes (AOPs) have been widely studied as a green alternative treatment for the purification of contaminated water [13-18]: Fenton and photo-Fenton reactions (induced by $\mathrm{Fe}(\mathrm{II}) / \mathrm{H}_{2} \mathrm{O}_{2}$ species without or with UV irradiation respectively) are widely studied and utilized to promote the degradation of organic contaminants through the action of highly oxidizing species, mainly hydroxyl radicals $(\cdot \mathrm{OH})$, generated in situ from $\mathrm{H}_{2} \mathrm{O}_{2}$ decomposition catalyzed by $\mathrm{Fe}(\mathrm{II})$-sources and accelerated by UV-vis irradiation $(\lambda<500 \mathrm{~nm}$, in the photoFenton process) [19]. Photo-Fenton processes are applied in treating several industrial wastewaters, such as dye industry [20], pesticides [21], phenols and organic compounds [22,23], and real contaminated effluents [24]. Additionally, as reported by Bauer et al. [25], photo-Fenton treatments are the cheapest one among the other available AOPs. Quite recently, several efforts were realized by worldwide experts to enhance the efficiency/feasibility of both Fenton and photo-Fenton processes by testing different materials [26,27], as well as different AOPs methods [28,29]. In particular, most of the problems related to the industrial scale up of such processes are both the $\mathrm{pH}$ correction and the reactants consumption [30-32], thus the possibility of using low-cost easilyremovable materials working at circumneutral $\mathrm{pH}$ is extremely promising. As evidenced in the literature, the introduction of humic-like substances in both Fenton and photo-Fenton processes seems to significantly favor the pollutant degradation capacity in aqueous environment at circumneutral $\mathrm{pH}$, even though the effective role played by humic-like substances in the oxidation mechanism is still not fully solved [6,8,33-34]. As reported in several studies, humic substances directly improve the degradation of organic pollutants under UV-vis irradiation in two different ways: either involving the triplet-excited states of the O-containing functionalities present in the humic-like structures [35], or through the formation of many reactive O-containing species, such as hydroxyl radicals, singlet oxygen $\left({ }^{1} \mathrm{O}_{2}\left(\mathrm{a}^{1} \Delta_{\mathrm{g}}\right)\right)$, and superoxide species $[6,36,37]$. Additionally, humic and humic-like substances not only favor the direct oxidation of organic pollutants, but also speed up the iron redox reactions $\mathrm{Fe}(\mathrm{II}) / \mathrm{Fe}(\mathrm{III})$, thus accelerating both Fenton and photo-Fenton mechanisms [38,39].

In this respect, it appears very convenient to use a combined approach to remove the organic contaminants in water applying bio-based substances together with an iron-source. Quite recently, magnetite (Fe(II)/Fe(III) mixed valence oxide), maghemite $\left(\gamma-\mathrm{Fe}_{2} \mathrm{O}_{3}\right)$, and hematite $\left(\alpha-\mathrm{Fe}_{2} \mathrm{O}_{3}\right)$ have been successfully verified as alternative sources of iron in heterogeneous AOPs [40,41]. If the iron source is magnetite or another magnet-sensitive material, it becomes also possible to recover the species active in the removal of contaminants from aqueous matrices after the treatment.
Magnetic materials are usually synthesized by coprecipitation method in basic medium (between 8 and 14) [40]. Respect to the stoichiometric ratio, a slight excess of $\mathrm{Fe}(\mathrm{II})$ in the synthesis is preferred to prevent the possible oxidation of $\mathrm{Fe}(\mathrm{II})$ atoms with formation of maghemite as impurity since the reaction mixture was exposed to the air. According to the literature [42], for $\mathrm{Fe}(\mathrm{III}) / \mathrm{Fe}$ (II) $<1.75$ pure magnetite NPs are obtained, whereas for $\mathrm{Fe}(\mathrm{III}) / \mathrm{Fe}$ (II) $\geqslant 1.75$ the final product consists of a mixture of magnetite and maghemite. Additionally, since magnetite is sensitive to oxidation, maghemite can be easily formed by topotactic oxidation of magnetite due to aging phenomena $[43,44]$. In order to avoid the complete oxidation of magnetite/maghemite phases to hematite, the stabilization with an organic coating is usually carried out $[43,45,46]$. In general, the addition of chelating anions (i.e. carboxylate or hydroxyl-carboxylate species) or polymeric complexing agents (such as chitosan, dextran, starch, or polyvinyl alcohol) during the formation/precipitation of magnetite can both drive the nanoparticles size-control as well as enhance the iron oxide stability (in particular, preserving magnetite from oxidation). Also biomasses and residual biowaste-derived substances have been considered as source of organic coating [40] valorizing urban and/or agricultural biowastes into added-value chemicals (thus reentering them into the economic cycle) [47].

Therefore, the aim of this study is the use of Bio-Based Substances obtained from Green Compost (BBS-GC) as synthesis intermediates/stabilizers for the production of BBS-covered magnetite nanoparticles. Such BBS are lignin-derived supramolecular aggregates with a very complex structure similar to humic-like substances (namely, aromatic and aliphatic chains functionalized with acid and basic functional groups whose chemical structure is fully reported in Table S1). Three different synthesis formulations were investigated.

The application of such BBS-coated magnet-sensitive nanoparticles was investigated in heterogeneous Fenton-like and photoFenton-like processes for wastewater treatments, taking caffeine (a stimulating agent) as model EPs.

\section{Experimental}

\subsection{Materials}

Magnetite precursors were anhydrous ferric chloride $\mathrm{FeCl}_{3}$ (CAS 7705-08-0, purity $\geqslant 98 \%$. Fluka Chemika) and ferrous sulphate heptahydrate $\mathrm{FeSO}_{4} 7 \mathrm{H}_{2} \mathrm{O}$ (CAS 7782-63-0, purity $\geqslant 99.5 \%$, Fluka Chemika). Bio-Based Substances (BBS-GC) were isolated from composted urban biowastes (urban public park trimming and home gardening residues) aged for more than 180 days, obtained from the ACEA Pinerolese Industriale S.p.A. waste treatment plant located in Pinerolo (Italy). Other reagents used were: ammonium hydroxide solution (CAS 1336-21-6, $\mathrm{NH}_{3}$ essay $28-30 \%$, E. Merck), caffeine $\left(\mathrm{C}_{8} \mathrm{H}_{10} \mathrm{~N}_{4} \mathrm{O}_{2}\right.$, CAS 58-08-2, purity $\geqslant 99.0 \%$, Sigma-Aldrich), hydrogen peroxide $\left(\mathrm{H}_{2} \mathrm{O}_{2}\right.$, CAS 7722-84-1, essay 31\%, Anedra Research AG), methanol HPLC grade $\left(\mathrm{CH}_{3} \mathrm{OH}\right.$, CAS 67-56-1, essay $99.8 \%$, Sintorgan), phosphoric acid $\left(\mathrm{H}_{3} \mathrm{PO}_{4}\right.$, CAS $7664-38-2$, essay $84-86 \%$, Cicarelli Laboratorios), 1,10-phenanthroline (o-phenanthroline, $\mathrm{C}_{12} \mathrm{H}_{8} \mathrm{~N}_{2}$, CAS 66-71-7, purity $\geqslant 99.0 \%$, Sigma-Aldrich), and ammonium phosphate $\left(\mathrm{NH}_{4} \mathrm{H}_{2} \mathrm{PO}_{4}\right.$, CAS 7722-76-1, essay $\geqslant 99.0$, SigmaAldrich). All aqueous solutions for HPLC analysis were prepared using ultrapure water Millipore Milli- $Q^{\mathrm{TM}}$. All chemicals were used without further purification.

\subsection{Preparation of magnetite/BBS nanoparticles}

BBS-stabilized magnetite nanoparticles were synthesized following a modified procedure already reported in the literature 
$[40,43]$. In detail, $3.7 \mathrm{~g}$ of $\mathrm{FeCl}_{3}$ and $4.17 \mathrm{~g}$ of $\mathrm{FeSO}_{4} 7 \mathrm{H}_{2} \mathrm{O}$ (molar ratio $\mathrm{Fe}(\mathrm{III}) / \mathrm{Fe}(\mathrm{II})=1.5$ ) were dissolved in $100 \mathrm{~mL}$ of deionized water and heated up to $90^{\circ} \mathrm{C}$. Once the target temperature was reached, two solutions were added simultaneously: a) $10 \mathrm{~mL}$ of 25 vol.\% ammonium hydroxide, and b) $50 \mathrm{~mL}$ of a previously prepared BBS aqueous solution. In particular, three BBS-containing solutions with different content of BBS were employed: 1,2 , and 3 wt.\%, respectively. The final mixture was mechanically stirred at isothermal conditions $\left(90^{\circ} \mathrm{C}\right)$ for $30 \mathrm{~min}$ and then cooled down to room temperature (RT). In this way a dispersion of BBSstabilized magnetic iron oxide nanoparticles has been directly obtained in a one-step process by co-precipitation method. Such dark-brown solutions were: i) purified by washing twice with deionized water, ii) deposited onto glass Petri dishes, and iii) oven-dried at $80^{\circ} \mathrm{C}$ overnight. The resulting magnetic materials were manually crumbled. Depending on the different wt.\% of BBS (namely $1 \mathrm{wt} . \%, 2 \mathrm{wt} . \%$ and $3 \mathrm{wt} . \%$ ), the obtained nanoparticles were coded with the acronym MB1, MB2 and MB3, respectively). Non-stabilized magnetite (M0), obtained from the already described procedure without BBS addition, was taken as neat magnetite reference.

\subsection{Physicochemical characterizations}

Scanning electron microscopy (SEM) analyses were carried out by using a ZEISS EVO 50 XVP microscope with LaB $_{6}$ source, equipped with detectors for secondary electron collection. SEM micrographs were performed after sputtering the samples with a gold layer (ca. $10 \mathrm{~nm}$ thickness, Bal-tec SCD050 sputter coater). Additionally, the particles size distribution was evaluated on SEM micrographs at $150,000 \times$ magnification by using the software Particule2 (version 2.0) and calculating the diameter size on 500 nanoparticles. The nanoparticles diameter values are corrected with respect to the gold coating thickness.

Magnetization measurements were carried out with a LakeShore 7404 vibrating sample magnetometer. The hysteresis loop of the samples was registered at RT and the magnetic field was cycled between $-20,000$ and 20,000 Gauss.

$\mathrm{N}_{2}$ adsorption-desorption experiments were carried out by using an ASAP 2020 instrument (Micromeritics) in order to determine the specific surface area (BET model) [48] and porosity (BJH model) of all samples [49]. Samples (ca. $0.5 \mathrm{~g}$ ) were previously outgassed at $70^{\circ} \mathrm{C}$ for about $24 \mathrm{~h}$ in vacuum (residual pressure $10^{-2}$ mbar) to ensure the complete removal of atmospheric contaminants from their surface before the analysis.

Fourier transform infrared (FTIR) spectra were recorded in transmission mode by means of a Bruker Vector 22 spectrophotometer equipped with Globar source, DTGS detector, and working with 128 scans at $4 \mathrm{~cm}^{-1}$ resolution in the $4000-400 \mathrm{~cm}^{-1}$ range. Samples were dispersed in $\mathrm{KBr}$ (1:20 wt ratio).

X-ray diffraction (XRD) patterns were obtained by means of an X'Pert PRO MPD diffractometer from PANalytical, equipped with $\mathrm{Cu}$ anode, working at $45 \mathrm{kV}$ and $40 \mathrm{~mA}$, in a Bragg-Brentano geometry performing experiments on flat sample-holder configurations. The acquisition was performed in a $0.02^{\circ}$ interval steps, with $45 \mathrm{~s}$ step $^{-1}$ to obtain a good signal to noise ratio. The magnetite particles size was also estimated by means of the Scherrer equation (Eq. (1)):

$\tau=\frac{K \lambda}{\beta \cos \theta}$

were $\tau$ is the mean size of the crystalline domains (expressed in $\mathrm{nm}$ ), $\mathrm{K}$ is a shape factor (typical value adopted is 0.9 ), $\lambda$ is the $\mathrm{X}$-ray wavelength $(0.154 \mathrm{~nm}), \beta$ is the line broadening at half the maximum intensity (FWHM) of the selected Bragg angle after subtracting the instrumental line broadening (expressed in radians), and $\theta$ is the Bragg angle (expressed in radians). For the magnetite NPs size quantification, the Bragg angle selected is the magnetite reflection (311) at ca. $2 \theta=35.6^{\circ}$.

Colorimetric quantification of free-Fe(II) was performed using a double-beam T90+ UV-vis spectrometer (PG Instruments Ltd), in a quartz cuvette, slow speed mode at $1 \mathrm{~nm}$ resolution in the 200$800 \mathrm{~nm}$ range. The conventional colorimetric tests were performed by mixing ca. $10 \mathrm{mg}$ of each sample with 0 -phenanthroline and acetate buffer $(\mathrm{pH}=4)$ forming the orange-red ferrous-tris-ophenanthroline complex [50]. The free-Fe(II) was quantified after 60 min of contact.

Thermo-gravimetric analyses (TGA) were carried out by means of an ultra-microbalance (sensitivity $0.1 \mu \mathrm{g}$ ) connected with both a time-resolved FTIR and a GC/MS detectors. Samples in powdery form (ca. $30 \mathrm{mg}$ ) were placed into an open platinum pan and heated from 30 to $900{ }^{\circ} \mathrm{C}$ at the heating rate of $10^{\circ} \mathrm{C} \mathrm{min}{ }^{-1}$ under dynamic nitrogen atmosphere (gas purity: 99.9995\%; flow rate: $35 \mathrm{~mL} \mathrm{~min}^{-1}$ ) by using a Perkin-Elmer Pyris 1 TGA instrument (Waltham, MA, USA). The exhausted gas (gas flow $65 \mathrm{~mL} \mathrm{~min}^{-1}$ ) was piped via a pressurized heated transfer line (Redshift S.r.l., Vicenza, Italy) and analyzed continuously by the FTIR detector (Spectrum 100, Perkin-Elmer), equipped with a thermostated conventional gas cell. Temperature/time-resolved spectra were acquired in the $4000-600 \mathrm{~cm}^{-1}$ wavenumber range with a $0.4 \mathrm{~cm}^{-1}$ resolution and analyzed with the Spectrum software (Perkin-Elmer). Temperature-resolved infrared profiles of each single species desorbed from the analyzed samples were obtained measuring the intensity of a representative peak of the investigated species at a selected wavenumber. The $\varepsilon$ values were obtained employing "PPM/Meter Gas Cell Concentration Data" from Specac (Orpington, UK) which was obtained by measuring the gases in a one meter path-length gas cell at $25^{\circ} \mathrm{C}$ at 1 atmosphere pressure with a nitrogen gas mix. The absorbance value given for the concentration of gas was expected at the indicated wavenumber position (i.e. $2360 \mathrm{~cm}^{-1}$ due to the asymmetric stretching mode of $\mathrm{CO}_{2}$ and $960 \mathrm{~cm}^{-1}$ due to the symmetric bending mode of $\mathrm{NH}_{3}$ ). The absorbance reported was 0.40 a.u. for $\mathrm{CO}_{2}$ $(100 \mathrm{ppm})$, and 0.12 a.u. for $\mathrm{NH}_{3}(100 \mathrm{ppm})$. On the basis of these data, we calculated the absorption coefficients (namely $\mathrm{ECO}_{2}=4.0$ $\cdot 10^{-3} \mathrm{ppm}^{-1} \mathrm{~m}^{-1}$, and $\mathrm{ENH}_{3}=1.2 \cdot 10^{-3} \mathrm{ppm}^{-1} \mathrm{~m}^{-1}$ ) by applying the Lambert-Beer's law. In our experimental determinations, the maximum intensity point due to the asymmetric stretching mode of $\mathrm{CO}_{2}$ was recorded at $2359 \mathrm{~cm}^{-1}$, while the maximum intensity point due to the symmetric bending mode of $\mathrm{NH}_{3}$ occurred at $965 \mathrm{~cm}^{-1}$ [51].

\subsection{Fenton-like and photo-Fenton-like degradation of caffeine}

Degradation experiments were performed: i) for Fenton-like tests, in a closed Pyrex-flask (containing $200 \mathrm{~mL}$ solution at RT) covered with an aluminum paper (i.e. in the dark) under continuous magnetic stirring, or ii) for photo-Fenton-like tests, in a cylindrical Quartz vessel (diameter: $5 \mathrm{~mm}$, containing $200 \mathrm{~mL}$ solution, at $32.5 \pm 2.5^{\circ} \mathrm{C}$ ) under continuous magnetic stirring. Experiments were performed in two replicas and the average profiles were reported. The initial concentration of the caffeine was $5 \mathrm{mg} \mathrm{L}^{-1}$. Experiments were performed by addition of $100 \mathrm{mg}$ of NPs (neat magnetite or BBS-stabilized samples) in presence of hydrogen peroxide $\left(\mathrm{H}_{2} \mathrm{O}_{2}, 0.4 \mathrm{mM}\right)$. The amount of hydrogen peroxide added was chosen considering half the stoichiometric concentration which is enough to reach an efficient caffeine degradation, as suggested in the literature [52]. To verify the natural photolysis of caffeine, experiments in presence of only $\mathrm{H}_{2} \mathrm{O}_{2}$ were also performed. The effect of the hydroxyl radicals was evaluated performing experiments in presence of the BBS-stabilized NPs and in absence of $\mathrm{H}_{2} \mathrm{O}_{2}$, whereas in order to evaluate the importance of the 
magnetite-core in the NPs, control experiments in homogeneous phase (i.e., $100 \mathrm{mg}$ of $\mathrm{BBS}$ and $0.4 \mathrm{mM} \mathrm{H}_{2} \mathrm{O}_{2}$ ) were also realized. The possible effect of free-Fe(II) release was evaluated by performing experiments in absence of NPs and by addition of $\mathrm{Fe}(\mathrm{II})$ at the concentration quantified for MB2 by colorimetric tests. Finally, the effect of UV irradiation was checked performing Fenton experiments in the dark. Reactions were run at the $\mathrm{pH}=6$, which did not change during experiments. A photochemical reactor (Rayonet RPR-100) equipped with 8 RPR-3500 A lamps with emission centered at $350 \mathrm{~nm}$ was used as irradiation source (for photo-Fenton tests). The incident photon rate $\left(3.50 \times 10^{-5}\right.$ Einstein $\left.\mathrm{L}^{-1} \mathrm{~s}^{-1}\right)$ was measured using a potassium ferrioxalate actinometer (see Fig. S1). During each experiment, $3 \mathrm{~mL}$ sample aliquots were periodically collected at fixed time from the flask/vessel. Before analysis, aliquots were magnet-cleaned (in order to avoid the presence of the magnetic nanoparticles) and filtered through nylon membranes with $0.45 \mu \mathrm{m}$ cut-off.

The caffeine concentration was determined by means of high pressure liquid chromatography (HPLC), using a Hewlett-Packard TI series 1050 HPLC system with auto-sampler and multiwavelength detection, equipped with a Inertsil ODS-3 column ( $4.6 \mathrm{~mm} \times 250 \mathrm{~mm}$, spherical particles size $5 \mu \mathrm{m}$ in size, modified with end-capped octadecyl groups, $\mathrm{pH}$ ranging in the 2.0-7.5 interval). The eluent was a $1 \% \mathrm{H}_{3} \mathrm{PO}_{4}$ in $50 / 50$ (vol.\%) methanol/water mixture at $0.8 \mathrm{~mL} \mathrm{~min}^{-1}$ constant flux. The injection volume was $50 \mu \mathrm{L}$ with a re-equilibration time of $10 \mathrm{~min}$. The caffeine detection wavelength was $275 \mathrm{~nm}$.

UV-Visible spectra of caffeine solution before and after degradation were recorded by means of a double-beam T90 + UV-vis spectrometer (PG Instruments Ltd) with slow speed at $1 \mathrm{~nm}$ resolution in the $200-800 \mathrm{~nm}$ range.

\section{Results and discussion}

\subsection{Morphological, physicochemical and magnetic characterization}

Nitrogen sorption measurements were performed on both pure magnetite and BBS-stabilized samples, and results are summarized in Table 1. All the isotherms (not reported for the sake of brevity) show a profile IV, with a hysteresis loop of type H3 (according to the IUPAC classification) in the relative pressure range $0.4-1$. The BET surface area of the reference magnetite (MO) is $77 \mathrm{~m}^{2} \mathrm{~g}^{-1}$, whereas all BBS-stabilized samples present a very low specific surface area and mesopores volume, ranging values from $4 \mathrm{~m}^{2} \mathrm{~g}^{-1}$ (MB1) up to $33 \mathrm{~m}^{2} \mathrm{~g}^{-1}$ (MB3). This particular behavior clearly confirmed that the presence of BBS dramatically influences both the aggregation and the porosity in the final material (vide infra for the sample composition).

Infrared spectra of both reference materials (neat magnetite M0 and neat BBS) and MB2 (MB1 and MB3 are not shown for the sake of brevity) are collected in Fig. 1. In particular, the presence of BBS

Table 1

BET surface areas, BJH pore volumes and magnetite NPs size estimated by Scherrer equation applied on the XRD (311) magnetite main reflection.

\begin{tabular}{llll}
\hline Samples & $\begin{array}{l}\text { BET surface area } \\
\left(\mathrm{m}^{2} \mathrm{~g}^{-1}\right)\end{array}$ & $\begin{array}{l}\text { BJH pore volume } \\
\left(\mathrm{cm}^{3} \mathrm{~g}^{-1}\right)\end{array}$ & $\begin{array}{l}\text { NPs mean size } \\
(\mathrm{nm})^{\mathrm{a}}\end{array}$ \\
\hline M0 & 77 & 0.24 & $18 \pm 3$ \\
MB1 & 4 & 0.03 & $27 \pm 4$ \\
MB2 & 16 & 0.08 & $22 \pm 6$ \\
MB3 & 33 & 0.06 & $16 \pm 1$ \\
\hline
\end{tabular}

a Calculated by substituting in Eq. (1) the line broadening at half the maximum intensity of the (311) magnetite reflection peak. Two different measurements are performed and average values are calculated. Diameters are reported in $\mathrm{nm} \pm$ standard deviation. in MB2 is mainly confirmed by the carboxylate stretching mode at ca. $1600 \mathrm{~cm}^{-1}$. The band at $1120 \mathrm{~cm}^{-1}$ is typical of $\mathrm{C}-\mathrm{O}$ stretching mode of organic matter (i.e. polysaccharides and other BBSderived substances) adsorbed onto the iron oxide surface. Magnetite phase is clearly evidenced by signals at 575 and $620 \mathrm{~cm}^{-1}$ due to Fe-O stretching vibrations. Significant differences were observed by comparing the FTIR spectra in the region relative to carboxylic/carboxylate functionalities [40] evidencing the interaction between BBS-carboxylate anions and the iron oxide surface. As already evidenced by Ou and coworkers [53] for humic substances, in all BBS-stabilized NPs it was observed the formation of a very sharp band at $1400 \mathrm{~cm}^{-1}$ associated with the carboxylate-iron bond stretching. Other signals in the range $900-700 \mathrm{~cm}^{-1}$ not evidenced in the figure are due to ammonium-containing salts, which are byproducts of the co-precipitation reaction.

$\mathrm{X}$-ray diffraction (XRD) patterns were used to identify the iron oxide phases presented in all samples (Fig. 2). Even in this case, only the MB2 sample was discussed, since similar results were obtained for the other BBS-stabilized samples. All the crystalline planes reflection registered for MB2 sample at $2 \theta=30.1^{\circ}(220)$, $35.4^{\circ}(311), 43.0^{\circ}(400), 53.9^{\circ}(422) 57.2^{\circ}(511)$, and $62.6^{\circ}$ (440) are consistent with the presence of magnetite phase (reference code 00-019-0629, ICCD Database) [44]. The signals not related to magnetite phase (main relevant one at $2 \theta=33^{\circ}$ ) are consistent with the presence of ammonium-containing salts, namely ammonium chloride (reference code 01-073-0363, ICCD Database), confirming the FTIR results.

In order to estimate the average particle size, Scherrer formula applied to the (311) magnetite signal was used (see Table 1). The size of the crystalline domains related to magnetite phase are not homogeneous (all the signals are quite broad) and a slight decrease in the calculated average NPs size was observed in the BBS-stabilized samples from MB1 to MB3. In particular, it is possible to note that the size of the crystalline domains decreases increasing the BBS concentration. A possible explanation of this behavior can be found in the action developed by BBS in the synthesis. It is added to the reaction mixture just after the beginning of the coprecipitation reaction (i.e. right after the formation of the crystal seeds) and it covers the crystals avoiding their agglomeration. If the amount of biosurfactant is high, its presence not only

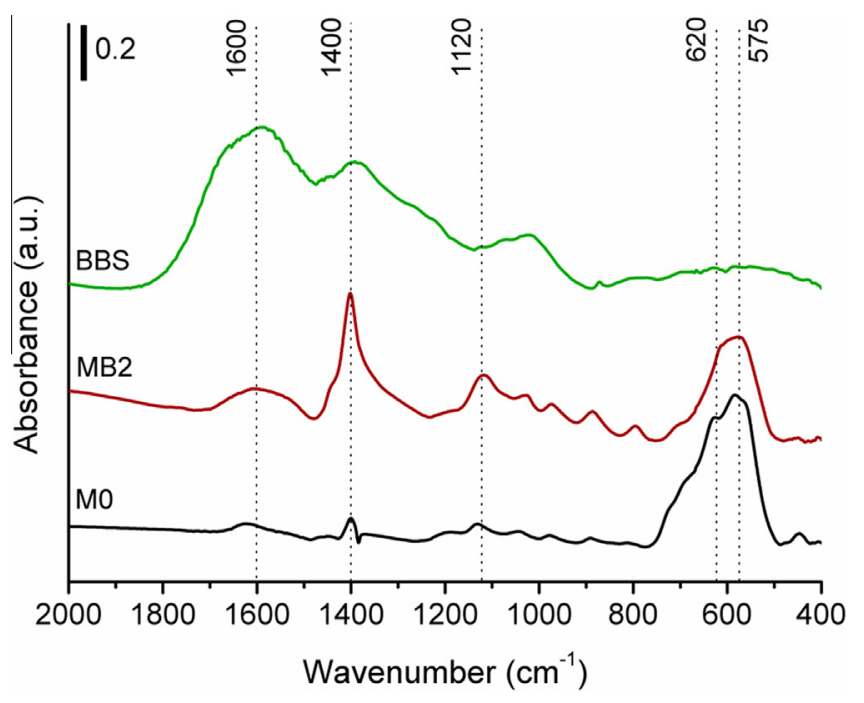

Fig. 1. Absorbance FTIR spectra in the $2000-400 \mathrm{~cm}^{-1}$ range relative to neat BBS (green), neat magnetite M0 (black), and BBS-stabilized MB2 (red). The main relevant peaks are labeled. All spectra are collected in transmission mode through $\mathrm{KBr}$ pellets. (For interpretation of the references to colour in this figure legend, the reader is referred to the web version of this article.) 


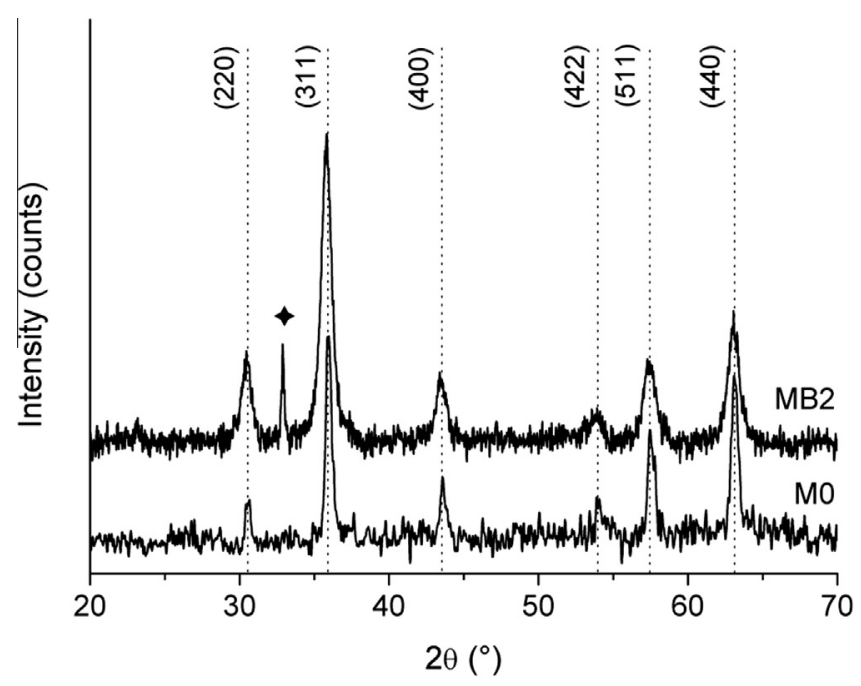

Fig. 2. XRD patterns of the neat magnetite (M0) and BBS-stabilized sample (MB2) The main reflections due to magnetite are highlighted and labeled. Black symbol refers to the ammonium chloride phase (byproduct).

avoids the agglomeration of the particles but also limits the growth of the crystals which remain small.

The morphology of all BBS magnet-sensitive NPs, dispersed in water and deposited on sample holder, was evaluated by means of SEM (TEM image of MB1 is reported in [40]). Considering the similarity shown by the samples, only MB2 images are reported in Fig. 3. In detail, MB2 material appeared as aggregates of roughly spherical particles (see Fig. 3A) whose size distribution is reported in Fig. 3B. MB2 particles show diameters in the range $16-55 \mathrm{~nm}$, with the $40 \%$ of the particles centered between 26 and $30 \mathrm{~nm}$. These values are in very good agreement with those calculated from Scherrer equation for the same sample (i.e. $22 \pm 6 \mathrm{~nm}$ ), also considering that Scherrer calculation considers only the magnetite crystalline core without taking into account the organic coating around the particles.

Considering the magnetic behaviors, all BBS-stabilized samples are easily recoverable from their aqueous dispersions through the action of a permanent magnet. Moreover, dried BBS-stabilized materials do not lose their magnetic properties for at least one year, due to the BBS protective coating. Magnetization curves collected at RT of all samples are resumed in Fig. 4. Basing on the results obtained, all samples exhibit superparamagnetic behaviors, with almost zero remanence (Mr) and very low coercitivity (Hc below $10 \mathrm{G}$ ). The saturation magnetization (Ms) of all BBS-stabilized magnet-sensitive NPs were 53 (MB1), 36 (MB2), and 30 (MB3) emu $g^{-1}$, respectively. The decrease in Ms for all

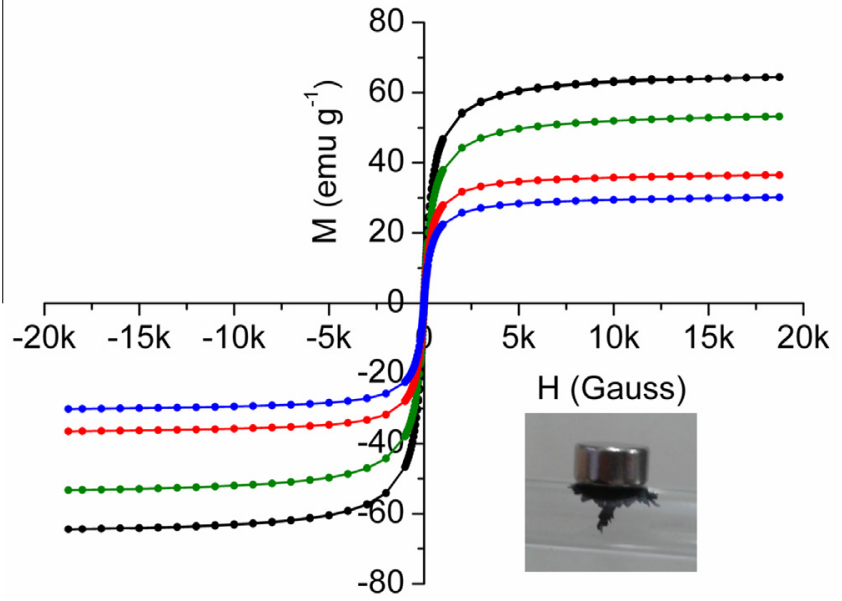

Fig. 4. Magnetization curves evaluation of neat magnetite and BBS-stabilized samples. Legend: M0 (black), MB1 (green), MB2 (red), and MB3 (blue). Inset shows the magnetic response of the BBS-stabilized materials vs. a commercially available neodymium magnet. (For interpretation of the references to colour in this figure legend, the reader is referred to the web version of this article.)

the samples compared to the reference magnetite M0 $\left(64 \mathrm{emu} \mathrm{g}^{-1}\right)$ is due to the presence of the organic coating as well as to a different average size of magnetic domains (Table 1). According to the literature, the presence of a coating agent decreases the materials uniformity due to quenching phenomena of surface moments, thus inducing a reduction of magnetic moments in the nanoparticles $[40,54]$. Moreover, the decrease of the Ms as decreasing the particle size is due to the increasing of the surface spin canting due to increasing disorder of the adsorbed species as the particles decrease in size [55].

\subsection{Thermal stability and BBS degradation profiles}

Neat BBS and BBS-stabilized nanoparticles thermal behaviors were analyzed by TGA in the temperature range $30-900{ }^{\circ} \mathrm{C}$ under flow of $\mathrm{N}_{2}$ in order to establish the thermal stability of the samples and to determine the BBS amount in the hybrid materials. $\mathrm{NH}_{3}$ and $\mathrm{CO}_{2}$ evolved during the heating ramp were continuously monitored by the FTIR detector coupled to the gravimetric apparatus. FTIR profiles of the evolved species, expressed as $\mathrm{ppm} / \mathrm{mg}$ of sample, were determined relating the IR absorbance measured at a specific wavenumber (i.e. $965 \mathrm{~cm}^{-1}$ for $\mathrm{NH}_{3}$ and $2359 \mathrm{~cm}^{-1}$ for $\mathrm{CO}_{2}$ ) to their concentration according to the Lambert-Beer law relationship employing the spectra of each species at a known concentration from the instrument database. In Fig. 5 are reported both the weight loss\% and its derivative curve (panel A), together
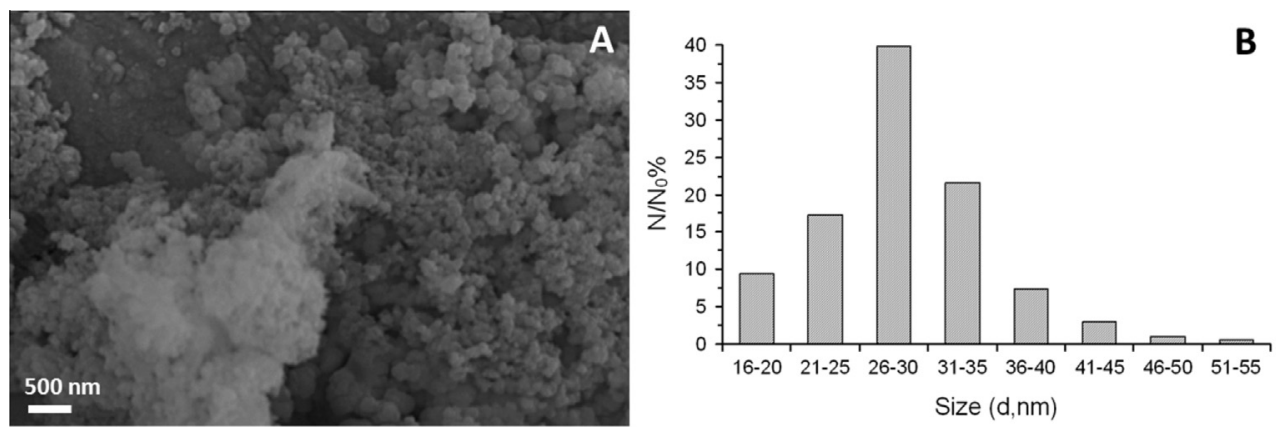

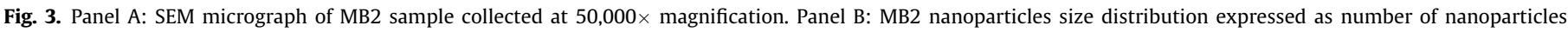
percentage $\left(\mathrm{N} / \mathrm{N}_{0} \%\right.$, where $\mathrm{N}_{0}$ is the total of nanoparticles considered, i.e. 500$)$. 
with the FTIR profiles (panel B) of $\mathrm{NH}_{3}$ and $\mathrm{CO}_{2}$ evolved during the heating of MB2. These data were compared to those obtained with pure BBS at the same experimental conditions. TGA analysis of BBS presented two main weight losses: the first one was due to moisture content (water evaporation), as highlighted by the minimum at ca. $100{ }^{\circ} \mathrm{C}$ on the derivative curve, whereas the second one, which occurred between 250 and $600{ }^{\circ} \mathrm{C}$, was principally due to the degradation of the BBS-organic matter, but also the presence of inorganic contributions need to be considered. A carbonaceous residue (containing some inorganic ashes), which represented ca. the $50 \%$ of the starting sample, was collected in the pan after the heating ramp.

The thermal degradation of MB2 shows three main degradation steps evidenced by the three minima on the derivative curve at ca. 230,310 and $430{ }^{\circ} \mathrm{C}$, due to degradation of both ammoniumcontaining salts (as byproducts of the synthesis, according to FTIR and XRD analyses) and BBS coating. In addition, in the temperature range between 700 and $900{ }^{\circ} \mathrm{C}$ an important weight loss was recorded and attributed to the chemical reduction of magnetite
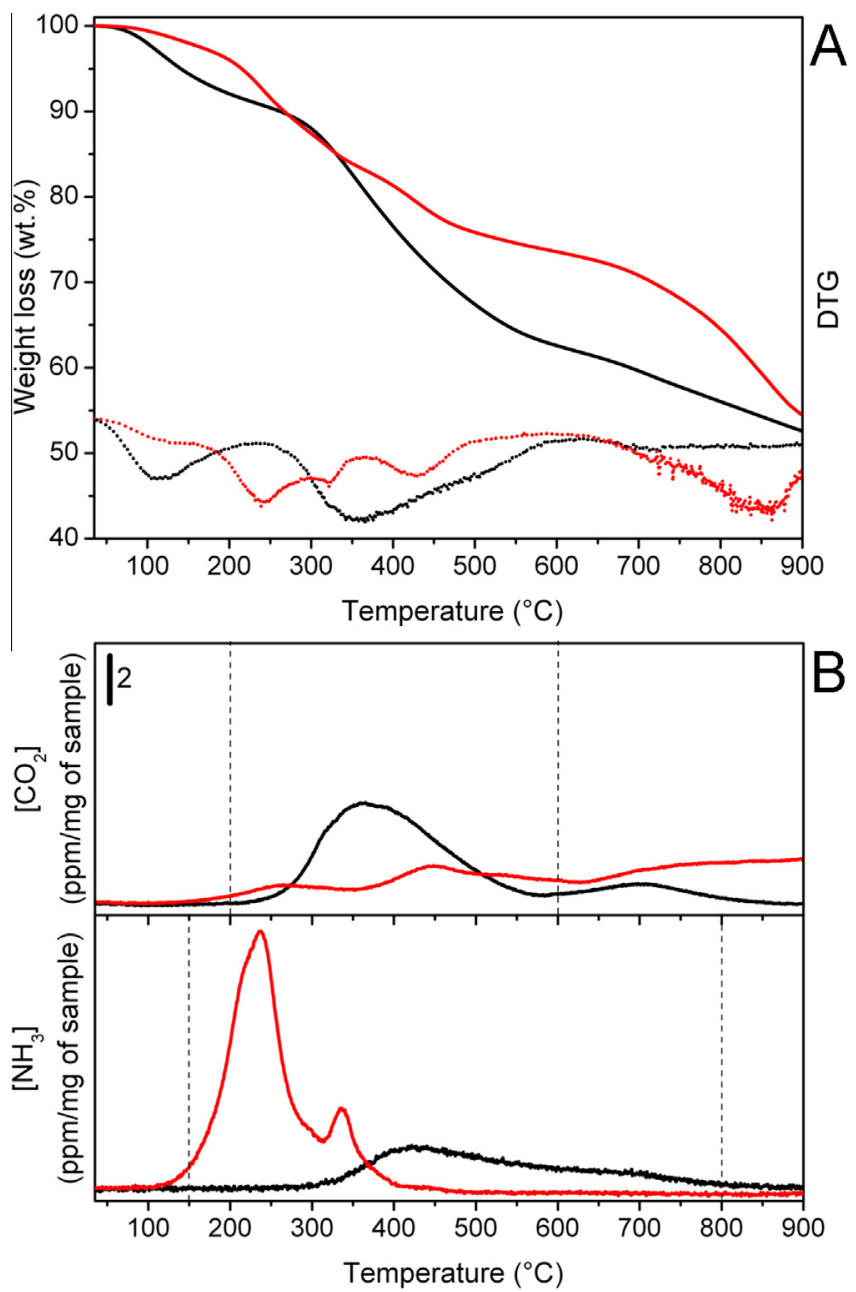

Fig. 5. Panel A, TGA (solid line) and the derivative (dotted line) curves of the neat BBS (black) and MB2 (red) heated from 30 to $900{ }^{\circ} \mathrm{C}$ at $10^{\circ} \mathrm{C} \mathrm{min}^{-1}$ under dynamic nitrogen atmosphere. Panel B, FTIR profiles of the volatile $\mathrm{CO}_{2}$ and $\mathrm{NH}_{3}$ products released from neat BBS (black) and MB2 (red) during the heating ramp expressed as a function of temperature. Each curve represents the concentration (expressed as $\mathrm{ppm} / \mathrm{mg}$ of sample) of the species evolved and it is obtained relating the IR absorbance at a specific wavenumber to the concentration by the Lambert-Beer's law relationship: $\mathrm{CO}_{2}\left(2359 \mathrm{~cm}^{-1}\right)$, and $\mathrm{NH}_{3}\left(965 \mathrm{~cm}^{-1}\right)$. (For interpretation of the references to colour in this figure legend, the reader is referred to the web version of this article.) into wüstite $(\mathrm{FeO})$ under the adopted reducing conditions (nitrogen flux) [43].

During the heating ramp, the evolution of $\mathrm{NH}_{3}$ and $\mathrm{CO}_{2}$ species released from the sample was monitored by FTIR detector. It is evinced that the evolution of $\mathrm{CO}_{2}$ from neat $\mathrm{BBS}$ takes place via a two-step process since two maxima are evidenced in the $\mathrm{CO}_{2}$ release curve, whereas the same experiment carried out with MB2 evidenced that $\mathrm{CO}_{2}$, which reasonably comes from the decarboxylation of the BBS organic component, is released through a single broad step. The release of $\mathrm{NH}_{3}$ from BBS is attributed to the decomposition of both $\mathrm{N}$-containing functionalities and ammonium-containing ashes (ash content: $31.2 \mathrm{wt} . \%$, see the Table S1). Also, the rather high amount of $\mathrm{NH}_{3}$ released at lower temperature $\left(150-400^{\circ} \mathrm{C}\right)$ by $\mathrm{MB} 2$ sample should be due to the decomposition of ammonium-containing synthesis byproducts (in accordance to FTIR and XRD analyses). Analogue results have been obtained with both MB1 and MB3 (data not shown for brevity).

The percentage composition of materials (in terms of BBS, ashes, ammonium-containing salts and magnetite) was quantified by the following procedure:

I. Integrating the FTIR profile in the temperature range 200$600{ }^{\circ} \mathrm{C}$ (for $\mathrm{CO}_{2}$ ) and $150-800$ (for $\mathrm{NH}_{3}$ ). The starting temperature chosen for $\mathrm{CO}_{2}$ integration corresponds to the first degradation step.

II. Calculating the (BBS + ashes) wt.\% in each MB sample on the basis of the $\mathrm{CO}_{2}$ released, normalized to the $\mathrm{CO}_{2}$ released by neat BBS.

III. According to Table S1, the ashes content in BBS is $31.2 \mathrm{wt} . \%$ and thus the real BBS organic fraction forming the stabilizing coating was assumed to be complementary (i.e. the $68.8 \mathrm{wt}$. $\%$ of the BBS + ashes fraction).

IV. Estimating the byproduct content in this way: a) the difference of the total $\left[\mathrm{NH}_{3}\right]$ released from each material and the theoretical $\left[\mathrm{NH}_{3}\right]$ due to the (BBS + ashes) fraction in the sample was calculated, b) such $\left[\mathrm{NH}_{3}\right]$ difference was expressed as ammonium-salts wt.\% as a proportion respect to the total $\left[\mathrm{NH}_{3}\right]$ released by the reference $\mathrm{NH}_{4}^{+}$ containing salt (i.e. $\mathrm{NH}_{4} \mathrm{H}_{2} \mathrm{PO}_{4}$ ).

V. Finally the residual wt.\% was assigned to the iron oxide fraction in the sample.

The results obtained are summarized in Table 2. Since the amount of volatile products released by the samples is proportional to the composition of the material, we can estimate the relative content of BBS and magnetite in the hybrids.

The results evidenced that the increase of BBS concentration in the synthesis produces a decrease of the BBS loading in the obtained material. And this behavior is also sustained by the BET surface area variation and the average magnetite size calculated by Scherrer formula. This odd result can actually be explained considering that BBS in aqueous solution tends to organize in supramolecular arrays in a micellization process, due to its amphiphilic properties, and this probably affects the loading capacities $[8,12,56]$.

The content of byproducts ( $\mathrm{NH}_{4}^{+}$-containing salts, quantified by volatile $\mathrm{NH}_{3}$ species expressed as amount of $\mathrm{NH}_{4} \mathrm{H}_{2} \mathrm{PO}_{4}$ ) confirms the FTIR and XRD results, since the samples purity increases by decreasing the concentration of BBS in the starting solution (namely MB1 > MB2 > MB3).

To further clarify the mechanism of the organic substrate thermal degradation, the gas evolved during the BBS pyrolysis via TGA at the temperature corresponding to the maximum speed of the degradative process (i.e. $350{ }^{\circ} \mathrm{C}$ ) was analyzed by GC/MS. This experimental approach was chosen to unveil the presence of vola- 
Table 2

Evolved volatile species measured by TGA-FTIR analysis and data elaboration.

\begin{tabular}{|c|c|c|c|c|c|c|c|c|}
\hline \multirow[t]{2}{*}{ Samples } & \multicolumn{3}{|c|}{$\begin{array}{l}\text { Evolved volatile species measured by TGA-FTIR } \\
\text { analysis }\end{array}$} & \multicolumn{5}{|c|}{ Composition (wt.\%) } \\
\hline & Wt. (mg) & {$\left[\mathrm{CO}_{2}\right]^{\mathrm{a}}$} & {$\left[\mathrm{NH}_{3}\right]^{\mathrm{b}}$} & BBS & Ashes & $\mathrm{NH}_{4}^{+}$-salts & $\mathrm{Fe}_{3} \mathrm{O}_{4}$ & $\mathrm{BBS} / \mathrm{Fe}_{3} \mathrm{O}_{4}$ ratio \\
\hline BBS & 22.757 & 753.511 & 398.289 & 68.8 & 31.2 & - & - & - \\
\hline $\mathrm{NH}_{4} \mathrm{H}_{2} \mathrm{PO}_{4}$ & 31.823 & - & 4244.004 & - & - & 100.0 & - & - \\
\hline MB1 & 21.329 & 352.934 & 187.249 & 34.4 & 15.6 & 0.0 & 50.0 & 0.7 \\
\hline MB2 & 44.953 & 380.574 & 414.590 & 17.6 & 8.0 & 3.6 & 70.9 & 0.2 \\
\hline MB3 & 46.674 & 120.823 & 903.055 & 5.4 & 2.4 & 13.5 & 78.7 & 0.1 \\
\hline
\end{tabular}

a Calculated by integrating the $\mathrm{CO}_{2}$ profile in the range of temperature $200-600{ }^{\circ} \mathrm{C}$ (expressed as ppm/mg of sample).

b Calculated by integrating the $\mathrm{NH}_{3}$ profile in the range of temperature $150-800{ }^{\circ} \mathrm{C}$ (expressed as ppm/mg of sample).

tile organic specie which might be produced as intermediate during the pyrolysis. The GC/MS analysis did not evidence the release of organic molecule (data not reported for brevity) indicating that the pyrolysis of the BBS organic structure induces the formation only of small molecules (including $\mathrm{CO}_{2}$ and $\mathrm{NH}_{3}$ ) mainly due to BBS functional groups loss, thus leaving a carbonaceous residue, very promising for the production of carbon-based materials.

\subsection{The magnetite/BBS photo-activity in Fenton and photo-Fenton conditions}

Preliminary experiments were performed in order to evaluate the potential application of BBS-stabilized magnetite nanoparticles towards the degradation of caffeine (reference EP) at the natural $\mathrm{pH}$ (ca. 5-6) in Fenton-like and photo-Fenton-like processes. Upon UV irradiation in the presence of $\mathrm{H}_{2} \mathrm{O}_{2}$ (Fig. $6 \mathrm{~A}$ ) or $\mathrm{BBS} / \mathrm{H}_{2} \mathrm{O}_{2}$, no significant degradation of caffeine was observed (Fig. 6B, top). Such results allow to hypothesize that in the adopted experimental conditions, there is neither efficient generation of $\cdot \mathrm{OH}$ by $\mathrm{H}_{2} \mathrm{O}_{2}$ photolysis nor relevant production of reactive species by BBS photoactivation. The presence of neat magnetite and $\mathrm{H}_{2} \mathrm{O}_{2}$ slightly favored the degradation of caffeine (87\% of residual caffeine after $60 \mathrm{~min}$, as reported in Fig. 6A) in agreement with the literature data [41].

On the contrary, the addition of BBS-stabilized magnetic NPs in the presence of $\mathrm{H}_{2} \mathrm{O}_{2}$ dramatically changes the degradation behavior, evidencing different efficiency depending on the initial BBS concentration used to prepare the different NPs. In particular (Fig. 6A), the caffeine degradation profile observed in the presence of MB1 is comparable to the one observed when using neat M0. MB2 promotes the almost complete caffeine degradation after $60 \mathrm{~min}$ under UV irradiation (5\% of residual caffeine after $60 \mathrm{~min}$ ), as demonstrated by the UV-vis spectra of caffeine solution reported in Fig. 6C; the performance of MB3 is lower (60\% of residual caffeine after $60 \mathrm{~min}$ ). In order to give a rationale for the observed behavior, data reported in Table 2 could give a help: the less efficient NPs (MB1) contains the relative highest amount of BBS and the lowest magnetite amount; MB2 and MB3 contain a comparable magnetite amount, while MB2 has higher BBS content. Several previous studies dealing with the use of magnetitebased materials in Fenton/photo-Fenton-like processes (see [57] and references therein), reported that the efficiency of the photoFenton-like process with magnetite depends greatly on the dissolution of iron from the solid and the oxidation proceeds mostly via homogeneous Fenton. Moreover, the presence of chelating agents (e.g. EDTA, oxalate, tartrate, citrate) facilitates the dissolution of iron from the solid, thanks to the formation of iron complexes, thus favoring the homogeneous reaction. In the present case BBS contain carboxylic and phenolic group able to form iron complexes thus favoring the iron dissolution and the occurrence of photo-Fenton-like process. At the same time it can be hypothesized that, above a certain concentration, the scavenging of reac- tive species by BBS becomes relevant; such a behavior has been already discussed for BBS in homogeneous system [58,59]. Based on this, MB2 composition could represent the best compromise among several different operating mechanisms; nevertheless being the system highly complicated and several equilibria involved, further research is needed.

Based on the observed performance we focused our attention on MB2 sample for further experiments.

The capacity of MB2 in caffeine degradation was also evaluated under UV irradiation in the absence of $\mathrm{H}_{2} \mathrm{O}_{2}$ (Fig. 6B, bottom). In this case, the caffeine degradation was negligible, thus confirming the importance of $\mathrm{H}_{2} \mathrm{O}_{2}$ for the degradation process and further supporting the hypothesis of a photo-Fenton-like process, as main mechanism, excluding adsorption phenomena. Some experiments were therefore performed to assess the role of UV irradiation (i.e. in the dark, Fig. 6D). The results obtained evidence that the MB2 activity toward caffeine degradation in the absence of UV irradiation is significantly lower (ca. 65\% of residual caffeine after $60 \mathrm{~min}$ ).

In order to evaluate the relevance of homogeneous degradation process due to the possible presence of free-Fe(II) in solution, a colorimetric test with $o$-phenantroline has been performed and results are reported in Table S2 (calibration curve is reported in Fig. S2). It is evident that a not negligible amount of $\mathrm{Fe}(\mathrm{II})$ is released in solution $\left(0.001 \mathrm{~g} \mathrm{~L}^{-1}\right)$, thus allowing a homogeneous Fenton or photo-Fenton reactions to occur, justifying the caffeine degradation. In any case, the amount of Fe(II) released (with respect to the amount of sample) is similar for each sample under study, therefore the free-Fe(II) presence should not be the only factor favoring the caffeine degradation. Some experiments were then performed in the presence of $\mathrm{Fe}(\mathrm{II})$ (taking $\mathrm{FeSO}_{4} 7 \mathrm{H}_{2} \mathrm{O}$ as a source of $\mathrm{Fe}(\mathrm{II})$ ) at the same concentration of iron leached from MB2 (i.e. $0.001 \mathrm{~g} \mathrm{~L}^{-1}$, corresponding to $0.28 \% \mathrm{w} / \mathrm{w}$ of the magnetite content in MB2 in suspension) under both Fenton and photo-Fenton conditions at weak acid pH (ca. 6). Results evidence that the degradation of caffeine in presence of $\mathrm{Fe}(\mathrm{II})$ without BBS is significantly lower if compared to the same experiments performed in presence of MB2 material. In particular, in the presence of $\mathrm{Fe}(\mathrm{II})$ no relevant degradation is observed in Fenton conditions and ca. 70\% of abatement is registered after $60 \mathrm{~min}$ in photo-Fenton condition (MB2 sample caused $30 \%$ of abatement after $60 \mathrm{~min}$ in the dark and $95 \%$ in photochemical treatment), thus confirming the importance of BBS in the caffeine abatement. It could be hypothesized that the chelating groups present in BBS structure allow to stabilize iron species in solution, avoiding their conversion in the corresponding hydroxides. At the same time, the magnetite, stabilized by BBS, could be considered as an iron "reservoir" for the Fenton and photoFenton processes.

Actually, the effective role of BBS in the degradation process is still not fully understood, nevertheless BBS molecules seem to play as acceleration agent for the caffeine degradation, under both Fenton and photo-Fenton conditions. Moreover, BBS allow to carry out 

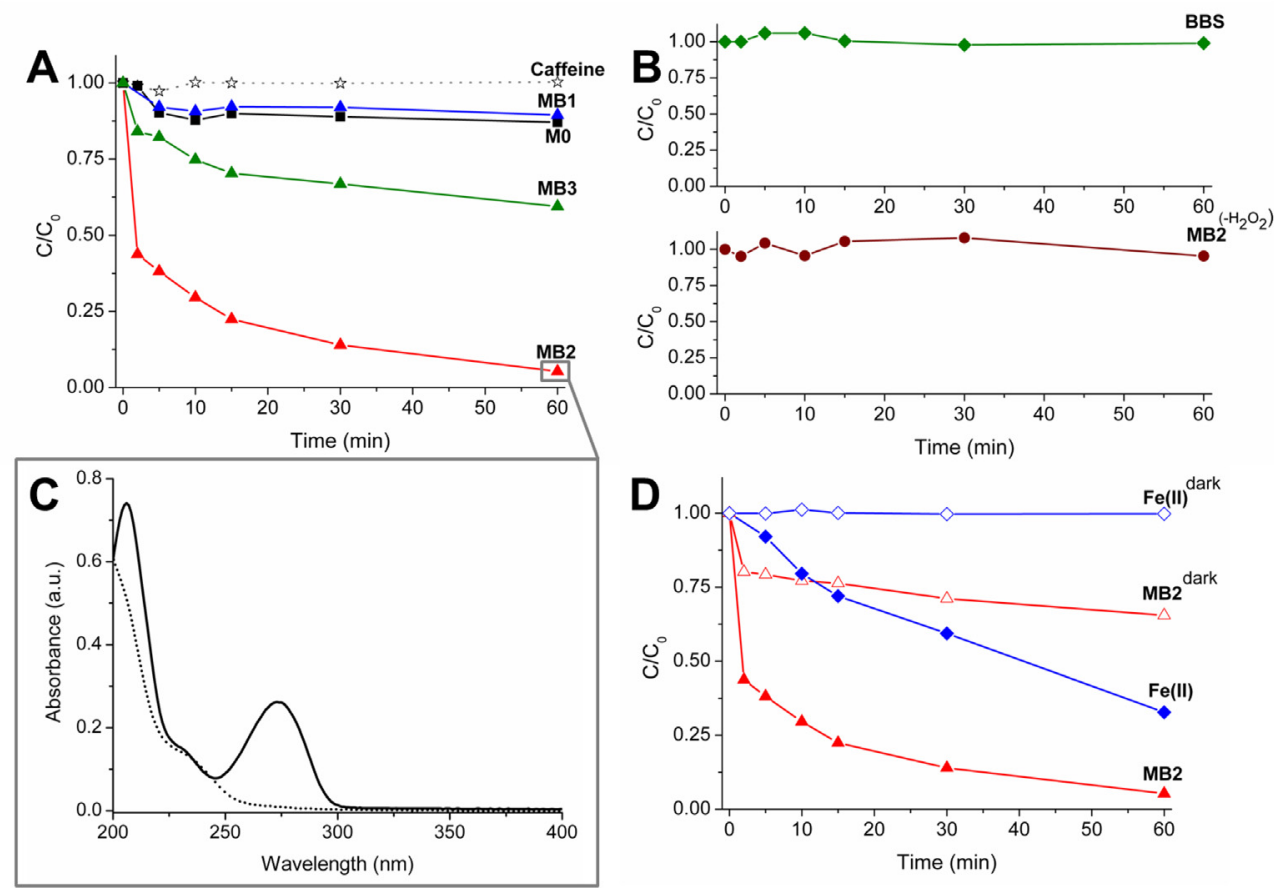

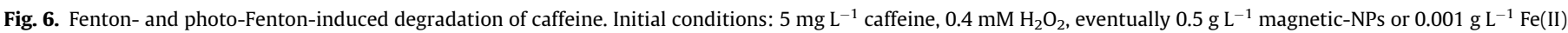

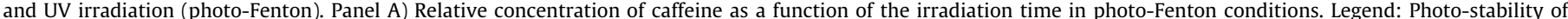

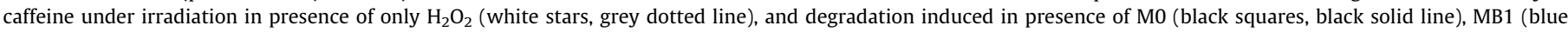

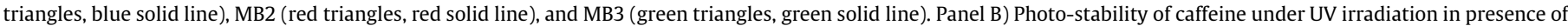

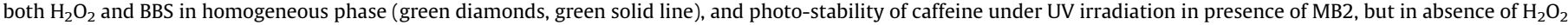

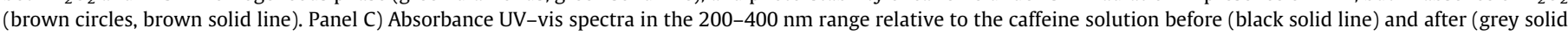

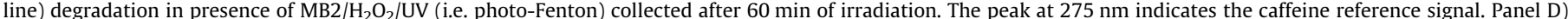

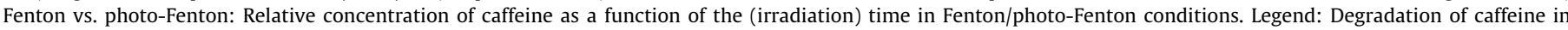

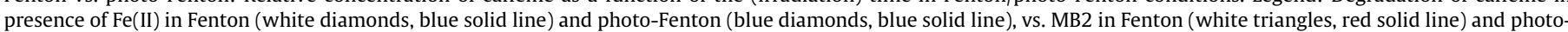

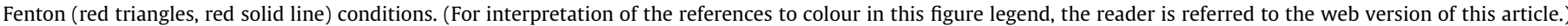

Fenton-based treatments (usually performed at very low $\mathrm{pH}$ ) in mild conditions (i.e. $\mathrm{pH}=6$ ), and this fact represents a relevant advance in wastewater treatments.

Some indications concerning the stability of BBS in homogeneous systems can be obtained from the literature [60], suggesting the possibility of reusing these materials in several cycles of reaction.

\section{Conclusions}

In conclusion, BBS (humic-like biopolymers derived from composted urban biowaste) have been proven to be effective stabilizing agent for the low-cost synthesis of magnet-sensitive nanoparticles, produced via co-precipitation method. Magnet-responsive NPs compared with other systems used for Fenton and photo-Fenton processes show the advantage of being easily recoverable from the reaction media using an external magnetic field.

Different amounts of BBS in the synthesis procedure has been investigated and a deep physicochemical characterization of such BBS-coated magnet-sensitive samples have been performed.

All samples are made of roughly spherical nanoparticles, which give rise to the formation of some aggregates with very low specific surface area and mesopores volume.

Magnetic properties showed that, even if the BBS coating decreases the saturation magnetization values (Ms) with respect to the neat magnetite, such BBS-coated materials are still highly magnet-sensitive and can be easily separated from their aqueous dispersions. Additionally, the natural oxidation involving the interconversion of magnetite into hematite is overcome due to the BBS preserving role. Magnetite stability was maintained for more than one year.

In wastewater treatment, even though it is still not fullyassessed the effective role of BBS, Fenton-like and photo-Fentonlike experiments highlight the peculiar capacity of BBS in promoting the caffeine degradation. The BBS-stabilized samples can be effective even at circumneutral $\mathrm{pH}$ in the presence of $\mathrm{H}_{2} \mathrm{O}_{2}$, upon UV irradiation

These preliminary tests evidence how BBS can be used as a promising green actor in wastewater purification treatments.

\section{Acknowledgements}

This work was realized with the financial support for academic interchange by the Marie Sklodowska-Curie Research and Innovation Staff Exchange project funded by the European Commission H2020-MSCA-RISE-2014 within the framework of the research project Mat4treaT (Project number: 645551). Compagnia di San Paolo and University of Torino are gratefully acknowledged for funding Project Torino_call2014_L2_126 through "Bando per il finanziamento di progetti di ricerca di Ateneo - anno 2014" (Project acronym: Microbusters). The TGA-FTIR-GCMS measures have been obtained with the equipment acquired by the "G. Scansetti" Interdepartmental Center for Studies on Asbestos and Other Toxic Particulates thanks to a grant by the Compagnia di San Paolo, Torino, Italy. Additionally, authors would like to acknowledge Dr. Flavio R. Sives (La Plata, Argentina) for magnetization measurements, together with Dr. Janina A. Rosso and Ms. Francisca Aparicio (La Plata, Argentina) for their precious help. 


\section{Appendix A. Supplementary data}

Supplementary data associated with this article can be found, in the online version, at http://dx.doi.org/10.1016/j.cej.2016.10.120.

\section{References}

[1] B.W. Atkinson, F. Bux, H.C. Kasan, Considerations for applications of biosorption technology to remediate metal-contaminated industrial effluents, Water SA 24 (1998) 129-135.

[2] A.K. Kivaisi, The potential for constructed wetlands for wastewater treatment and reuse in developing countries: a review, Ecol. Eng. 16 (2001) 545-560.

[3] S.D. Richardson, T.A. Ternes, Water analysis: emerging contaminants and current issues, Anal. Chem. 86 (2014) 2813-2848.

[4] L. Demarchis, M. Minella, R. Nisticò, V. Maurino, C. Minero, D. Vione, PhotoFenton reaction in the presence of morphologically controlled hematite as iron source, J. Photochem. Photobiol. A 307 (2015) 99-107.

[5] B. Petrie, R. Barden, B. Kasprzyk-Hordern, A review on emerging contaminants in wastewaters and the environment: current knowledge, understudied areas and recommendations for future monitoring, Water SA 72 (2015) 3-27.

[6] N. Klamerth, S. Malato, M.I. Maldonado, A. Agüera, A. Fernández-Alba, Modified photo-Fenton for degradation of emerging contaminants in municipal wastewater effluents, Catal. Today 161 (2011) 241-246.

[7] A.B.A. Boxall, New and Emerging Water Pollutants arising from Agriculture, OECD Publishing, 2012, http://www.oecd.org/tad/sustainable-agriculture/ 49848768.pdf.

[8] G. Magnacca, E. Laurenti, M.C. González, A. Arques, A. Bianco Prevot, Effect of humic substances and bioorganic substrates from urban wastes in nanostructured materials applications and synthesis, in: A. Arques, A. Bianco Prevot (Eds.), Soluble Bio-based Substances Isolated from Urban Wastes. Environmental Applications, Springer International Publishing AG, Cham (Switzerland), 2015, pp. 41-58.

[9] B. De Benedetti, A.C. Barbera, P. Freni, P. Tecchio, Wastewater valorization adopting the microalgae accelerated growth, Desalin. Water Treat. 53 (2015) 1001-1011.

[10] W.S. Wan Ngah, L.C. Teong, M.A.K.M. Hanafiah, Adsorption of dyes and heavy metal ions by chitosan composites: a review, Carbohydr. Polym. 83 (2011) 1446-1456.

[11] G. Magnacca, E. Laurenti, E. Vigna, F. Franzoso, L. Tomasso, E. Montoneri, V. Boffa, Refuse derived bio-organics and immobilized soybean peroxidase for green chemical technology, Process Biochem. 47 (2012) 2025-2031.

[12] R. Nisticò, M. Barrasso, G.A. Carrillo Le Roux, M.M. Seckler, W. Sousa, M. Malandrino, G. Magnacca, Biopolymers from composted biowaste as stabilizers for the green synthesis of spherical and homogeneously sized silver nanoparticles for textile application on natural fibers, ChemPhysChem 16 (2015) 3902-3909.

[13] A.G. Trovó, T.F.S. Silva, O. Gomes Jr., A.E.H. Machado, W. Borges Neto, P.S. Muller Jr., D. Daniel, Degradation of caffeine by photo-Fenton process: optimization of treatment conditions using experimental design, Chemosphere 90 (2013) 170-175.

[14] N. Klamerth, S. Malato, M.I. Maldonado, A. Aguera, A.R. Fernández-Alba Application of photo-Fenton as a tertiary treatment of emerging contaminants in municipal wastewater, Environ. Sci. Technol, 44 (2010) 1792-1798.

[15] N. Klamerth, L. Rizzo, S. Malato, M.I. Maldonado, A. Aguera, A.R. FernándezAlba, Degradation of fifteen emerging contaminants at $\mu \mathrm{g} \mathrm{L}^{-1}$ initia concentrations by mild solar photo-Fenton in MWTP effluents, Water Res. 44 (2010) 545-554.

[16] C. Sirtori, A. Zapata, I. Oller, W. Gernjak, A. Agüera, S. Malato, Decontamination industrial pharmaceutical wastewater combining solar photo-Fenton and biological treatment, Water Res. 43 (2009) 661-668.

[17] A. Zapata, I. Oller, L. Rizzo, S. Hilgert, M.I. Maldonado, J.A. Sánches-Pérez, S. Malato, Evaluation of operating parameters involved in solar photo-Fenton treatment of wastewater: interdependence of initial pollutant concentration temperature and iron concentration, Appl. Catal. B 97 (2010) 292-298.

[18] A. Bernabeu, S. Palacios, R. Vicente, R.F. Vercher, S. Malato, A. Arques, A.M. Amat, Solar photo-Fenton at mild conditions to treat a mixture of six emerging pollutants, Chem. Eng. J. 198-199 (2012) 65-72.

[19] A. Babuponnusami, K. Muthukumar, A review on Fenton and improvements to the Fenton process for wastewater treatment, J. Environ. Chem. Eng. 2 (2014) 557-572.

[20] J. Feng, X. Hu, P.L. Yue, H.Y. Zhu, G.Q. Lu, Degradation of azo-dye Orange II by a photoassisted Fenton reaction using a novel composite of iron oxide and silicate nanoparticles as a catalyst, Ind. Eng. Chem. Res. 42 (2003) 2058-2066.

[21] H. Fallmann, T. Krutzler, R. Bauer, S. Malato, J. Blanco, Applicability of the photo-Fenton method for treating water containing pesticides, Catal. Today 54 (1999) 309-319.

[22] L. Yu, J. Chen, Z. Liang, W. Xu, L. Chen, D. Ye, Degradation of phenol using $\mathrm{Fe}_{3} \mathrm{O}_{4}-\mathrm{GO}$ nanocomposite as a heterogeneous photo-Fenton catalyst, Sep. Purif. Technol. 171 (2016) 80-87.

[23] S. Giannakis, M.I. Polo López, D. Spuhler, J.A. Sánchez Pérez, P. Fernández Ibáñez, C. Pulgarin, Solar disinfection is an augmentable, in situ-generated photo-Fenton reaction-Part 2: a review of the applications for drinking water and wastewater disinfection, Appl. Catal. B 198 (2016) 431-446.
[24] S. Miralles-Cuevas, I. Oller, A. Agüera, J.A. Sánchez Pérez, S. Malato, Strategies for reducing cost by using solar photo-Fenton treatment combined with nanofiltration to remove microcontaminats in real municipal effluents: toxicity and economic assessment, Chem. Eng. J. (2016), in press.

[25] R. Bauer, H. Fallmann, The photo-Fenton oxidation - a cheap and efficient wastewater treatment method, Res. Chem. Intermed. 23 (1997) 341-354.

[26] B. Bethi, S.H. Sonawane, B.A. Bhanvase, S.P. Gumfekar, Nanomaterials-based advanced oxidation processes for wastewater treatment: a review, Chem. Eng. Process. 109 (2016) 178-189.

[27] S. Lacombe, T. Pigot, Materials for selective photo-oxygenation vs. photocatalysis: preparation, properties and applications in environmental and health fields, Catalysis, Sci. Technol. 6 (2016) 1571-1592.

[28] S. Gligorovski, R. Strekowski, S. Barbati, D. Vione, Environmental implications of hydroxyl radicals ('OH), Chem. Rev. 115 (2015) 13051-13092.

[29] A. Babuponnusamia, K. Muthukumar, Advanced oxidation of phenol: a comparison between Fenton, electro-Fenton, sono-electro-Fenton and photoelectro-Fenton processes, Chem. Eng. J. 183 (2012) 1-9.

[30] S. Miralles-Cuevas, I. Oller, A. Agüera, J.A. Sánchez Pérez, R. Sánchez-Moreno, S. Malato, Is the combination of nanofiltration membranes and AOPs for removing microcontaminants cost effective in real municipal wastewater effluents?, Environ Sci. Water Res. Technol. 2 (2016) 511-520.

[31] T.F.C.V. Silva, A. Fonseca, I. Saraiva, R.A.R. Boaventura, V.J.P. Vilar, Scale-up and cost analysis of a photo-Fenton system for sanitary landfill leachate treatment, Chem. Eng. J. 283 (2016) 76-88.

[32] A. Buthiyappan, A.A.A. Raman, W.M.A.W. Daud, Development of an advanced chemical oxidation wastewater treatment system for the batik industry in Malaysia, RSC Adv. 6 (2016) 25222-25241.

[33] J. Gomis, R.F. Vercher, A.M. Amat, D.O. Mártire, M.C. González, A. Bianco Prevot, E. Montoneri, A. Arques, L. Carlos, Application of soluble bio-organic substances (SBO) as photocatalysts for wastewater treatment: sensitizing effect and photo-Fenton-like process, Catal. Today 209 (2013) 176-180.

[34] J. Gomis, L. Carlos, A. Bianco Prevot, A.C.S.C. Teixeira, M. Mora, A.M. Amat, R. Vicente, A. Arques, Bio-based substances from urban waste as auxiliaries for solar photo-Fenton treatment under mild conditions: optimization of operational variables, Catal. Today 240A (2015) 39-45.

[35] S. Canonica, Oxidation of aquatic organic contaminants induced by excited triplet states, Chimia 61 (2007) 641-644.

[36] P.P. Vaughan, N.V. Blough, Photochemical formation of hydroxyl radical by constituents of natural waters, Environ. Sci. Technol. 32 (1998) 2947-2953.

[37] A. Paul, S. Hackbarth, R.D. Vogt, B. Röder, B.K. Burnison, C.E.W. Steinberg, Photogeneration of singlet oxygen by humic substances: comparison of humic substances of aquatic and terrestrial origin, Photochem. Photobiol. Sci. 3 (2004) 273-280

[38] M. Moonshine, Y. Rudich, S. Katsman, E.R. Graber, Atmospheric HULIS enhance pollutant degradation by promoting the dark Fenton reaction, Geophys. Res. Lett. 25 (2008) L20807.

[39] B.M. Voelker, B. Sulzberger, Effects of fulvic acid on Fe(II) oxidation by hydrogen peroxide, Environ. Sci. Technol. 30 (1996) 1106-1114.

[40] G. Magnacca, A. Allera, E. Montoneri, L. Celi, D.E. Benito, L.G. Gagliardi, M.C. González, D.O. Mártire, L. Carlos, Novel magnetite nanoparticles coated with waste-sourced biobased substances as sustainable and renewable adsorbing materials, ACS Sustainable Chem. Eng. 2 (2014) 1518-1524.

[41] M. Minella, G. Marchetti, E. De Laurentiis, M. Malandrino, V. Maurino, C. Minero, D. Vione, K. Hanna, Photo-Fenton oxidation of phenol with magnetite as iron source, Appl. Catal. B 154-155 (2014) 102-109.

[42] W. Jiang, K.-L. Lai, H. Hu, X.-B. Zeng, F. Lang, K.-X. Liu, Y. Wu, Z.-W. Gu, The effect of $\left[\mathrm{Fe}^{3+}\right] /\left[\mathrm{Fe}^{2+}\right]$ molar ratio and iron salts concentration on the properties of superparamagnetic iron oxide nanoparticles in the water/ethanol/toluene system, J. Nanopart. Res. 13 (2011) 5135-5145.

[43] F. Cesano, G. Fenoglio, L. Carlos, R. Nisticò, One-step synthesis of magnetic chitosan polymer composite films, Appl. Surf. Sci. 345 (2015) 175-181.

[44] R.M. Cornell, U. Schwertmann, The Iron Oxides: Structure, Properties, Reactions, Occurrences and Uses, Wiley-VCH, Weinheim, Germany, 2003.

[45] Y. Li, D. Yuan, M. Dong, Z. Chai, G. Fu, Facile and green synthesis of core-shell structured magnetic chitosan submicrospheres and their surface functionalization, Langmuir 29 (2013) 11770-11778.

[46] T. Nardi, M. Sangermano, Y. Leterrier, P. Allia, P. Tiberto, J.-A.E. Månson, UVcured transparent magnetic polymer nanocomposites, Polymer 54 (2013) 4472-4479.

[47] C. Briens, J. Piskorz, F. Berruti, Biomass valorization for fuel and chemicals production - a review, Int. J. Chem. Reactor Eng. 6 (2008), http://dx.doi.org/ $10.2202 / 1542-6580.1674$

[48] S. Brunauer, P.H. Emmett, E. Teller, Adsorption of gases in multimolecular layers, J. Am. Chem. Soc. 60 (1938) 309-319.

[49] E.P. Barrett, L.G. Joyner, P.P. Halenda, The determination of pore volume and area distributions in porous substances. I. Computations from nitrogen isotherms, J. Am. Chem. Soc. 73 (1951) 373-380.

[50] W.B. Fortune, M.G. Mellon, Determination of iron with o-phenanthroline: a spectrophotometric study, Ind. Eng. Chem. Anal. Ed. 10 (1938) 60-64.

[51] I. Corazzari, R. Nisticò, F. Turci, M.G. Faga, F. Franzoso, S. Tabasso, G. Magnacca, Advanced physico-chemical characterization of chitosan by means of TGA coupled on-line with FTIR and GCMS: thermal degradation and water adsorption capacity, Polym. Degrad. Stab. 112 (2015) 1-9.

[52] M. Munoz, Z.M. de Pedro, J.A. Casas, J.J. Rodriguez, Assessment of the generation of chlorinated byproducts upon Fenton-like oxidation of chlorophenols at different conditions, J. Hazard. Mater. 190 (2011) 993-1000. 
[53] X. Ou, S. Chen, X. Quan, H. Zhao, Photochemical activity and characterization of the complex of humic acids with iron(III), J. Geochem. Explor. 102 (2009) 4955.

[54] D.K. Kim, M. Mikhaylova, Y. Zhang, M. Muhammed, Protective coating of superparamagnetic iron oxide nanoparticles, Chem. Mater. 15 (2003) 16171627.

[55] E.D. Smolensky, H.-Y.E. Park, Y. Zhou, G.A. Rolla, M. Marjańska, M. Botta, V.C. Pierre, Scaling laws at the nano size: the effect of particle size and shape on the magnetism and relaxivity of iron oxide nanoparticle contrast agents, J. Mater. Chem. B 1 (2013) 2818-2828.

[56] P. Savarino, E. Montoneri, S. Bottigliengo, V. Boffa, T. Guizzetti, D.G. Perrone, R. Mendichi, Biosurfactants from urban wastes as auxiliaries for textile dyeing, Ind. Eng. Chem. Res. 48 (2009) 3738-3748.

[57] M. Munoz, Z.M. de Pedro, J.A. Casas, J.J. Rodriguez, Preparation of magnetitebased catalysts and their application in heterogeneous Fenton oxidation - a review, Appl. Catal. B 176-177 (2015) 249-265.
[58] P. Avetta, F. Bella, A. Bianco Prevot, E. Laurenti, E. Montoneri, A. Arques, L. Carlos, Waste cleaning waste: photodegradation of monochlorophenols in the presence of waste derived organic catalysts, ACS Sustainable Chem. Eng. 1 (2013) 1545-1550.

[59] J. Gomis, A. Bianco Prevot, E. Montoneri, M.C. Gonzalez, A.M. Amat, D.O. Martire, A. Arques, L. Carlos, Waste sourced bio-based substances for solardriven wastewater remediation: Photodegradation of emerging pollutants, Chem. Eng. J. 235 (2014) 236-243.

[60] J. Gomis, M.G. Gonçalves, R.F. Vercher, M.C. Sabater, M.A. Castillo, A. Bianco Prevot, A.M. Amat, A. Arques, Determination of photostability, biocompatibility and efficiency as photo-Fenton auxiliaries of three different types of soluble bio-based substances (SBO), Catal. Today 252 (2015) 177-183. 